\title{
Behavioral, Psychological or Informational Intervention
}

National Cancer Institute

\section{Source}

National Cancer Institute. Behavioral, Psychological or Informational Intervention. NCI

Thesaurus. Code C63474.

The use of behavioral conditioning, counseling, and/or education to prevent or treat disease. 